\title{
The Potential Role of Photosensitizers in Fight against Mosquitoes: Phototoxicity of Rose Bengal against Culex Pipiens Larvae
}

\author{
Mohamed S. Younis ${ }^{a}$, Hanem F. Khater ${ }^{b}$, Atef H. Hussein ${ }^{a}$, Shaimaa M. farag ${ }^{c}$, Heba M \\ Aboelela $^{a}$, Gehan A. Rashed ${ }^{\text {a }}$
}

a Department of Parasitology, Faculty of Medicine, Benha University, Egypt. ${ }^{\mathrm{b}}$ Department of Parasitology, Faculty of Veterinary Medicine, Benha University, Egypt. ${ }^{\mathrm{c}}$ Department of Entomolgy, Faculty of Science, Ain Shams University, Egypt.

Correspondence to: Heba M Aboelela, Department of Parasitology, Faculty of Medicine, Benha University, Egypt.

Email:

heba.mahmoud@fmed.bu.edu.eg

Received: 23 April 2020

Accepted: 21 July 2020

\begin{abstract}
:
Background: The common house mosquito, Culex pipiens, is abundant in Egypt and act as a vector of pathogens of medical and veterinary importance. Aim: The present study aimed to compare the toxic effect of rose bengal a photosensitizer to that of chlorpyrifos, a commercially available larvicide against the early $3^{\text {rd }}$ larval instar of $C x$. pipiens. Methods: We compare the toxic effect of rose Bengal exposed to sunlight from 10 am to $4 \mathrm{pm}$ to that of chlorpyrifos, against the early $3^{\text {rd }}$ larval instar of $C x$. pipiens. Results: Treatments revealed dose-dependent mortality, reaching $100 \%$ after treatment with rose bengal for $6 \mathrm{hrs}$ and $90.6 \%$ for chlorpyrifos for $24 \mathrm{hrs}$. Six hours post-treatments, the LC50 of rose bengal and chlorpyrifos were $4.9 \times 10^{-6}$ and $4.9 \times 10^{-4}$, respectively; while the LC95 were $2.0 \times 10^{-3}$ and $4.0 \times 0^{-3}$, respectively. Based on the LC50 values of chlorpyrifos as a reference substance, rose bengal was found 100 times more potent than chlorpyrifos. The LT50 of rose bengal ranged from 34.8 to $1.1 \mathrm{hrs}$ post-treatment with $1 \times 10^{-6} \mathrm{M}$ and $1 \times 10^{-2}$, respectively. The LT50 values of chlorpyrifos ranged from 3065.9 to $6.1 \mathrm{hrs}$ after subjecting to $1 \times 10^{-4} \mathrm{M}$ and $1 \times 10^{-3}$, respectively. Conclusion: It could be concluded that rose bengal could be used to prevent mosquito bites and their associated diseases as an alternative to traditional insecticides and an eco-friendly larvicide.
\end{abstract}

Keywords: photodynamic treatment, sunlight, larvicides, Mosquitoes, Egypt 



\section{Introduction}

Dipterous insects cause serious public health problems for both humans and animals. Culex pipiens, the common house mosquitos (Diptera: Culicidae) is found in Egypt and applying synthetic pesticides is mainly used for its control. Cx. pipiens acts as a vector of West Nile virus, Rift valley fever virus, Japanese encephalitis virus, and filariasis (1).

Botanical insecticides have long been used as the main weapons against insect pests before using of synthetic insecticides, developed in the mid-1930s to 1950s. Applying mosquito repellent is used for prevention form mosquito bites and its associated diseases. Synthetic insecticides are efficient, speedy, easily used, and inexpensive.

Therefore, they replaced many natural control strategies like using botanicals, predators, and parasitoids. Repeated and inappropriate use of insecticides induced environmental contamination, toxicity to non-target organisms, development of pest resistance, and negative impact on animal and human health (2).

Cx. pipiens acquired resistance against insecticides in Egypt. Consequently, there is an urgent need to explore and utilize safe alternatives for its control (3).

The biorational insecticides for mosquito control are preferable for environmental protection and public concerns because they have limited or no adverse effects on the environment, non- target organisms including humans.

They include biochemicals insecticides (botanicals, insect growth regulators, insect pheromones, photoinsecticides, and inorganics); biological insecticides using of natural enemies as predators, nematodes, and pathogens (virus, bacteria, fungi, or protozoa); nanoinsecticides, and transgenic insecticides. Most of them are effectively controlled the Egyptian strain of $C x$. pipiens (4).

Photodynamic processes are used in plants as chemical defense weapons against the attack by herbivorous insects, and the same strategy is used by parasitic fungi to help break plant cell walls. Such photodynamic action is an emerging strategy for control of multidrugresistant microorganisms by producing singlet oxygen and/or reactive oxygen species (ROS) released from the interaction between photoactive compounds (photosensitizers) and light in the presence of molecular oxygen.

Although photodynamic control (PDC) of mosquitoes was first explored in 1928, PDC has started to regain its importance because of growing concerns about pesticide-resistant mosquitoes (5). 
A photosensitizer accumulates within the pest body, and exposure to visible light induces lethal photochemical reactions and death of the organism (6).

Halogenated xanthenes as rose bengal have proven to be effective photo-insecticides against several insect species (7). The aims of the present study were comparing the toxic effect of rose bengal as a photosensitizer insecticide to that of chlorpyrifos, a commercially available conventional larvicide, against the early $3^{\text {rd }}$ larval instars of Cx. pipiens, determination of lethal concentration (LC) and time (LT) values, and determination of the relative efficacy of rose bengal over chlorpyrifos.

\section{Materials and methods}

This clinical trial was done during the period from January 2019 to September 2019, after approval of the ethical committee of Benha Faculty of medicine.

\section{Insect}

Cx. pipiens mosquitoes were obtained from the Research and Training Center on Vectors of Diseases, Faculty of Science, Ain Shams University, Cairo, Egypt, and reared in laboratory according to that of Kasap and Demirhan (8) and modified by Umaru and Akogunma (9).

\section{Materials}

Chlorpyrifos (Dursban) is a commercially available insecticide, obtained from AGRINE SERVE-Agricultural products, Giza, Egypt. Rose bengal , Rosets, $\mathrm{C}_{20} \mathrm{H}_{4} \mathrm{Cl}_{4} \mathrm{I}_{4} \mathrm{O}_{5}$, is water-soluble pink dye, $(4,5,6,7$ Tetrachloro-3', 6'-dihydroxy-2', 4', 5', 7'tetraiodo-3H-spiro[isobenzofuran-1,9'xanthene]-3-one), obtained from LOBA Chemie, Mumbai, India.

\section{The light source and absorption spectra}

Sunlight was used as a source of illumination following the recommendation of Khater et al., (6) during the period from 10 am to $4 \mathrm{pm}$. The absorption spectra of rose bengal were studied using UVVIS spectrometer (PG instruments Limited- Model 80+). The absorption occurred at wavelengths ranged from 450 to $600 \mathrm{~nm}$ corresponding to the visible region (Vis). The maximum absorption occurred at $536 \mathrm{~nm}$ which, equivalent to the green spectrum; whereas the weakest absorption occurred at the $302 \mathrm{~nm}$ wavelength, corresponding to the Ultraviolet (UV) region (Fig.1).

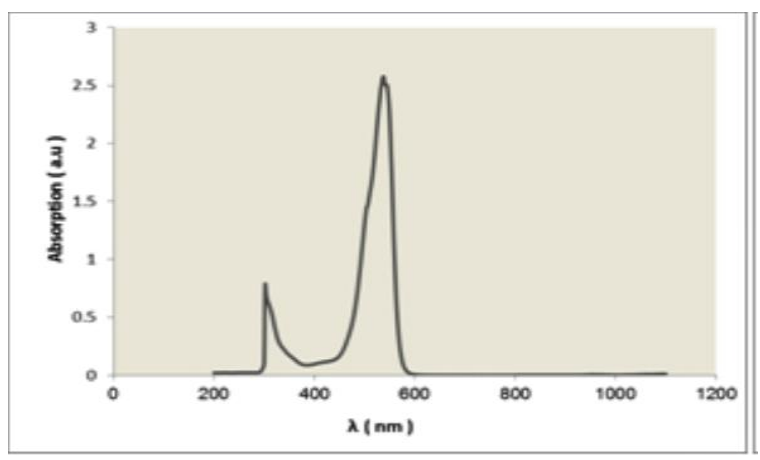

Fig.1: The absorption spectra of rose Bengal. 


\section{Bioassys}

A preliminary study was performed to define the range of concentrations. Bioassy was done according to that of the WORLD HEALTH ORGANIZATION (10). Early 3rd larval instars of $C x$. pipiens were used in this study. Four molar concentrations of each material were solved in dechlorinated water. Each concentration of the tested materials together with control groups were replicated three times, 25 larvae were used per replicate. Larvae were divided into four groups (Grs) as follows:

Gr. 1: Larvae were treated with rose bengal in different concentrations, $1 \times 10^{-2}, 1 \times 10^{3}, 1 \times 10^{-}$ ${ }^{4}$, and $1 \times 10^{-6}$, and exposed to sunlight from 10 am to $4 \mathrm{pm}$.

Gr. 2: Larvae were treated with chlorpyrifos in different concentrations, $1 \times 10^{-4}, 3 \times 10^{-4}$, $6 \times 10^{-4}$, and $1 \times 10^{-3}$, and exposed to sunlight as in group (1).

Gr. 3: Larvae were treated with rose bengal at concentrations applied in Group but kept in dark.

Gr. 4: Larvae were not treated and exposed to sunlight as Gr. 1.

Larval mortalities were recorded after 2, 4, 6, and 24 hours post-treatments.

\section{Data analysis}

$\mathrm{Z}$ test of two proportions was used to assess the significance among different concentrations at each time using Microstat software. Multiple comparisons were done $(\mathrm{P}=0.0083)$ according to that of Turner and Thayer (11).

Mortality data were subjected to Probit analysis (12) using the computer program Biostat (2009) for calculation of the lethal concentration (LC) values as well as of the lethal time (LT) values. The relative potency of rose bengal and chlorpyrifos were calculated according to the following formula and that of Zidan and Abdel-Mageed (13).

Relative potency $=L C$ value of chlorpyrifos /LC value of rose bengal

\section{Results}

Rose bengal absorbs sunlight at three regions including the Ultraviolet, Visible, and Infrared. The riches of sunlight occur in the visible region and the absorption spectra of rose bengal involved it. The intensity of the spectra from the sunlight is increasing during the period from 10 am to $4 \mathrm{pm}$.

Treatment of $3^{\text {rd }}$ larval instars of $C x$. pipiens with rose Bengal and chlorpyrifos revealed dose-dependent mortality, reaching 100\% after treatment with rose bengal for $6 \mathrm{hrs}$ and $90.6 \%$ for chlorpyrifos for $24 \mathrm{hrs}$. 

The present study indicated that there were no mortalities among larvae treated with different rose bengal concentrations and kept in the dark (Gr.3). Exposure of larvae to sunlight without treatment in the control light group (Gr.4) induced no mortalities among larvae (Table1).

Six hours post-treatments, the LC50 (lethal concentration, $50 \%$ ) values of rose bengal and chlorpyrifos were $4.9 \times 10^{-6}$ and $4.9 \times 10^{-4}$, respectively; while the LC95 (lethal concentration, 95\%) were $2.0 \times 10^{-3}$ and
$4.0 \times 0^{-3}$, respectively. Based on LC50 values of chlorpyrifos as a reference substance, rose bengal was found 100 times more potent than chlorpyrifos (Table 2).

The LT50 (the times required to kill 50\%) values of rose bengal ranged from 34.8 to 1.1 hrs post-treatment with $1 \times 10^{-6} \mathrm{M}$ and $1 \times 10^{-2}$, respectively. The LT50 values of chlorpyrifos ranged from 3065.9 to $6.1 \mathrm{hrs}$ after subjecting to $1 \times 10^{-4} \mathrm{M}$ and $1 \times 10^{-3}$, respectively (Table $3)$.

Table (1): The efficacy of tested compounds against early 3rd instar larvae of Cx. pipiens.

\section{Concs. (M) Mortality (\%)}

\section{Groups (Grs) and Tested Compounds}

\begin{tabular}{|c|c|c|c|c|c|}
\hline & & 2 & 4 & 6 & 24 \\
\hline & $1 \times 10^{-6}$ & 10.7 & 21.3 & 37.3 & 38.7 \\
\hline \multirow[t]{3}{*}{ Gr. (1): Rose bengal } & $1 \times 10^{-4}$ & $37.3 \mathrm{c}$ & $49.3 \mathrm{c}$ & $70.7 \mathrm{c}$ & $74.7 \mathrm{c}$ \\
\hline & $1 \mathrm{X} 10-^{3}$ & $62.7 \mathrm{ce}$ & $73.3 \mathrm{ce}$ & $94.7 \mathrm{ce}$ & $98.7 \mathrm{ce}$ \\
\hline & $1 \mathrm{X} 10^{2}$ & $81.3 \mathrm{ce}$ & $97.3 \mathrm{cef}$ & 100.0ce & 100ce \\
\hline \multirow[t]{4}{*}{ Group (2): Chlorpyrifos } & $1 \times 10^{-4}$ & 4 & 13.3 & 16 & 20 \\
\hline & $3 \times 10^{-4}$ & 6.6 & 14.6 & 22.6 & $56 e$ \\
\hline & $6 \times 10^{-4}$ & $25.3 \mathrm{eg}$ & $36 \mathrm{eg}$ & 56 eg & $77.3 \mathrm{e}$ \\
\hline & $1 \times 10^{-3}$ & $30.6 \mathrm{eg}$ & $66.6 \mathrm{egh}$ & $77.3 \mathrm{eg}$ & $90.6 \mathrm{eg}$ \\
\hline \multirow[t]{4}{*}{ Group (3): Rose Bengal in dark. } & $1 \times 10^{-6}$ & 0 & 0 & 0 & 0 \\
\hline & $1 \times 10^{-4}$ & 0 & 0 & 0 & 0 \\
\hline & $1 \times 10-^{3}$ & 0 & 0 & 0 & 0 \\
\hline & $1 \mathrm{X} 10^{2}$ & 0 & 0 & 0 & 0 \\
\hline Group (4): Control & 0 & 0 & 0 & 0 & 0 \\
\hline
\end{tabular}

\footnotetext{
Concs: means concentrations
}

$\mathrm{c}=$ sig in comparison with $1 \times 10^{-6}, \mathrm{e}=$ sig in comparison with $1 \times 10^{-4}, \mathrm{f}=\operatorname{sig}$ in comparison with $1 \mathrm{X} 10^{-3}, \mathrm{~g}=$ sig in comparison with $3 \times 10^{-4}, \mathrm{~h}=\operatorname{sig}$ in comparison with $6 \times 10^{-4}$, Multiple comparisons were done at adjusted $\mathrm{P}=0.0083$.

Larvae were treated and exposed to sunlight from 10am to 4pm except those in Gr. 3 
Table (2): Lethal concentration (LC) values (M) of rose Bengal and chlorpyrifos against early $3^{\text {rd }}$ instar larvae of $C x$. pipiens.

\begin{tabular}{|c|c|c|c|c|c|}
\hline $\begin{array}{l}\text { Tested } \\
\text { compounds }\end{array}$ & $\begin{array}{l}\text { Time/ PT } \\
\text { (hour) }\end{array}$ & $\begin{array}{c}\mathrm{LC}_{50} \\
\text { (Confidence limits) } \\
\end{array}$ & $\begin{array}{c}\mathrm{LC}_{95} \\
\text { (confidence limits) } \\
\end{array}$ & $\begin{array}{c}\mathrm{LC}_{99} \\
\text { (confidence limits) } \\
\end{array}$ & Slope \\
\hline \multirow[t]{8}{*}{ Rose bengal } & & $2.7 \times 10^{-4}$ & $3.0 \times 10^{-1}$ & 5.4 & 0.541 \\
\hline & 2 & $\left(1.4 \times 10^{-4}-5.4 \times 10^{-4}\right)$ & $\left(7.2 \times 10^{-2}-2.5\right)$ & $(0.8-100)$ & \pm 0.062 \\
\hline & & $4.7 \times 10^{-5}$ & $3.3 \times 10^{-2}$ & $4.9 \times 10^{-1}$ & 0.579 \\
\hline & 4 & $\left(3.9 \times 10^{-10}-2.1 \times 10^{-3}\right)$ & $\left(1.1 \times 10^{-3}-2.3 \times 10^{-1}\right)$ & $\left(5.7 \times 10^{-3}-7.0 \times 10^{11}\right)$ & \pm 0.061 \\
\hline & 6 & $4.9 \times 10^{-6}$ & $2.0 \times 10^{-3}$ & $2.5 \times 10^{-2}$ & 0.629 \\
\hline & & $\left(7.0 \times 10^{-11}-07.0 \times 10^{-5}\right)$ & $(1.2 \times 10-4-3.9 \times 10-1)$ & $\left(6.7 \times 10-4-7.7 \times 10^{12}\right)$ & \pm 0.070 \\
\hline & 24 & $3.7 \times 10^{-6}$ & $9.2 \times 10^{-4}$ & $9.1 \times 10^{-3}$ & 0.686 \\
\hline & & $\left(5.8 \times 10^{-19}-8.0 \times 10^{-5}\right)$ & $\left(5.0 \times 10^{-5}-9.8 \times 10^{-1}\right)$ & $\left(2.4 \times 10^{-4}-2.0 \times 10^{13}\right)$ & \pm 0.077 \\
\hline \multirow[t]{8}{*}{ Chlorpyrifos } & & $4 \times 10^{-3}$ & $1.2 \times 10^{-1}$ & $5 \times 10^{-1}$ & 0.541 \\
\hline & 2 & $\left(3.2 \times 10^{-2}-1 \times 10^{-2}\right)$ & $\left(4 \times 10^{-2}-3 \times 10^{-1}\right)$ & $\left(2 \times 10^{-1}-15 \times 10^{-1}\right)$ & \pm 0.062 \\
\hline & & $1 \times 10^{-3}$ & $1.2 \times 10^{-2}$ & $3 \times 10^{-2}$ & 0.579 \\
\hline & 4 & $\left(1.1 \times 10^{-6}-2 \times 10^{3}\right)$ & $\left(6 \times 10^{-3}-2 \times 10^{-2}\right)$ & $\left(1 \times 10^{-2}-7 \times 10^{-2}\right)$ & \pm 0.061 \\
\hline & 6 & $4.9 \times 10^{-4}$ & $4 \times 10^{-3}$ & $1 \times 10^{-2}$ & 0.629 \\
\hline & & $\left(1 . X 10^{-5}-1 X 10^{-3}\right)$ & $\left(3 \times 10^{-3}-8 \times 10^{-3}\right)$ & $\left(6 \times 10^{-3}-1.9 \times 10^{-2}\right)$ & \pm 0.070 \\
\hline & 24 & $2.5 \times 10^{-4}$ & $1.5 \times 10^{-3}$ & $3.2 \times 10^{-3}$ & 0.686 \\
\hline & & $\left(2.1 \times 10^{-4}-3 \times 10^{-3}\right)$ & $\left(1.1 \times 10^{-3}-2.4 \times 10^{-3}\right)$ & $\left(2.1 \times 10^{-3}-6.1 \times 10^{-3}\right)$ & \pm 0.077 \\
\hline $\mathbf{R E}^{1}$ & & 14.8 & & & \\
\hline $\mathbf{R E}^{2}$ & & 21.3 & & & \\
\hline $\mathbf{R E}^{3}$ & & 100 & & & \\
\hline $\mathbf{R E}^{4}$ & & 67.5 & & & \\
\hline
\end{tabular}

PT means post treatment

${ }^{1}$ Ratio of chlorpyrifos LC50: ratio of rose Bengal LC50 2hrs PT.

${ }^{2}$ Ratio of chlorpyrifos LC50: ratio of rose Bengal LC50 4hrs PT.

${ }^{3}$ Ratio of chlorpyrifos LC50: ratio of rose Bengal LC50 6hrs PT.

${ }^{4}$ Ratio of chlorpyrifos LC50: ratio of rose Bengal LC50 24hrs PT. 
Table (3): Median lethal time ( $\mathrm{LT}_{50}$ ) value, (per hour) and its 95\%confidence limits of rose bengal and chlorpyrifos.

\begin{tabular}{|c|c|c|c|}
\hline $\begin{array}{c}\text { Tested } \\
\text { compounds }\end{array}$ & Conc. (M) & $\begin{array}{c}\mathbf{L T}_{\mathbf{5 0}} \\
\text { (hours) }\end{array}$ & 95\% CI \\
\hline \multirow{5}{*}{ 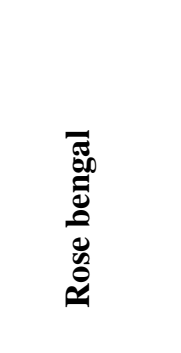 } & $1 \times 10^{-6}$ & 34.8 & $10.9-111.1$ \\
\hline & $1 \times 10^{-4}$ & 3.4 & $1.2-9.3$ \\
\hline & $1 \times 10^{-3}$ & 1.7 & $1.0-2.7$ \\
\hline & $1 \times 10-^{2}$ & 1.1 & $0.7-1.8$ \\
\hline & $1 \times 10^{-4}$ & 3065.9 & $239.1-39317.5$ \\
\hline \multirow{3}{*}{ 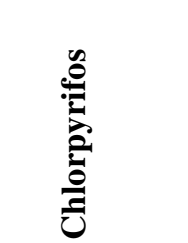 } & $3 \times 10^{-4}$ & 583.6 & 77.5- 4392.0 \\
\hline & $6 \times 10^{-4}$ & 18.2 & $9.7-34.1$ \\
\hline & $1 \times 10^{-3}$ & 6.1 & $3.0-12.4$ \\
\hline
\end{tabular}

\section{Discussion}

In Egypt, resistance strains of $C x$. pipiens larvae to insecticides were reported against Organophosphates (14) and a bacterial agent (15), hence it is very important to use alternative control strategies against it as photosensitizers. rose bengal showed a highly toxic effect against larvae of $C x$. pipiens. 100 $\%$ larvicidal effects were reached $6 \mathrm{hrs}$ posttreatment at concentration $1 \mathrm{x} 10-^{2} \mathrm{M}$, chlorpyrifos was found to be less toxic than rose bengal.

In agreement with the present results, rose bengal was the highly effective dye against instar larvae of Cx. Pipiens (16); Aedes triseriatus (17), Aedes aegypti, Anopheles stephensi, and Culex quinquefasciatus (18). Xanthene derivatives (a mixture of Rose bengal and Erythrosin) applied under artificial irradiation were the most efficient agents for Anopheles and Aedes larval control (19). Xanthene, chlorin, and porphyrin derivatives also exhibited larvicidal activity on Aedes aegypti, Anopheles stephensi, and Culex quinquefasciatus after photoactivation (18). In the same trend, a variety of photosensitizers are efficient mosquito larvicides (5).

Rose bengal is also effectively controlled the other pests as the adult house fly, Musca domestica (20); engorged females of Hyalomma dromedarii (21); and the $4^{\text {th }}$ larval instars of Spodoptera littoralis (22). After the addition of a specific hydrocarbon, rose bengal effectively controlled different stages of the onion fly, Hylemyia antiqua (23).

Our data indicated that rose bengal quickly killed larvae in the present study as indicated by the LT values. It excepted similar results 
against ticks (21). Rose bengal was 100 times more effectual than that of chlorpyrifos, $6 \mathrm{hrs}$ post-treatment. Similar relative potency over pesticides was reported (6).

The results in the present work revealed that exposure to sunlight alone (Gr. 4) and exposure to Rose bengal in the dark (Gr. 3) are not lethal to mosquito larvae. These results come along with that recommendation by Khater et al. (2016) of using sunlight instead of a light source. Phototoxicity occurs at the cellular level with the dye acting as a catalyst for the generation of singlet oxygen molecules leading to initiation of oxidation reactions that destroy several target molecules in the cell. To induce larval death by oxidative stress, a good photosensitizer (PS) should have efficient singlet oxygen or strong ROS generation (24).

The toxicity mechanisms triggered lethal energy stress by a photodynamic sensitizer against arthropods were summarized by Ben Amor and Jori (7) as follows: damaging the membranes of the midgut wall, alteration of the potassium levels in the hemolymph indicating changes in the membrane permeability, and physiological and morphological abnormalities at the larval, pupal, and adult stages affecting development and fecundity. More importantly, pests do not acquire resistance against photoactive compounds (25).
Concerning the safety of photosensitizers, they are inactive in the dark and do not accumulate because they are degraded by light. Sunlight-activated compounds are characterized by a low environmental impact and insignificant toxicological risk for humans, animals, or plants, (7).

Besides their pesticidal effect, photosensitizers have been shown to act as very efficient photodynamic agents against a broad number of microbial pathogens, including bacteria, fungi, and protozoa (26). This property has promising applications as water and blood disinfectants besides mosquito control (26). Photodynamic processes are used as food additives or therapeutic agents and address environmental problems such as the decontamination of wastewaters, the disinfection of fish-farming tanks, and protection of nontarget aquatic creatures as amphibians and reptiles form pathogens (27).

\section{Conclusion}

It could be concluded that rose bengal is highly effective when used at lower concentrations and short exposure times when compared to those of chlorpyrifos. Sunlight is an essential factor for the activation of rose Bengal; consequently, it is recommended to subject photosensitizers to sunlight at the regions from $300 \mathrm{~nm}$ to 600 $\mathrm{nm}$ for future work. Rose bengal could be 
applied to prevent mosquito bites and their associated diseases as an alternative to traditional insecticides and an eco-friendly larvicide.

\section{References}

1. El-Naggar AN, Elbanna SM, Kaiser MF, Gabre RM. Mosquito larval habitat mapping using remote sensing and GIS for monitoring the filarial infection regions in Alkorin village, Sharkia Governorate (Egypt). Inter J Mosq Res. 2017;4(4):135-9.

2. Khater HF, Selim AM, Abouelella GA, Abouelella NA, Murugan K, Vaz NP, et al. Commercial mosquito repellents and their safety concerns. In: Malaria. IntechOpen; 2019.

3. Shalaby AA, Khater HF. Toxicity of certain solvent extracts of Rosmarinus officinalis against Culex pipiens larvae. J Egypt Ger Soc Zool E. 2005;48:69-80.

4. Khater HF. Biocontrol of Some Insects [Ph. D. Dissertation]. Benha Branch Zagazig Univ Egypt. 2003;

5. Souza LM de, Inada NM, Pratavieira S, Corbi JJ, Kurachi C, Bagnato VS. Efficacy of Photogem ${ }($ Hematoporphyrin Derivative) as a photoactivatable larvicide against Aedes aegypti (Diptera: Culicidae) larvae. J Life Sci. 2017;11(2):7481.

6. Khater $\mathrm{H}$, Hendawy $\mathrm{N}$, Govindarajan $\mathrm{M}$, Murugan K, Benelli G. Photosensitizers in the fight against ticks: safranin as a novel photodynamic fluorescent acaricide to control the camel tick Hyalomma dromedarii (Ixodidae). Parasitol Res. 2016;115(10):3747-58.

7. Amor T Ben, Jori G. Sunlight-activated insecticides: historical background and mechanisms of phototoxic activity. Insect Biochem Mol Biol. 2000;30(10):915-25.

8. Kasap M, Demirhan O. The effect of various larval foods on the rate of adult emergence and fecundity of mosquitoes. Turkiye Parazitol Derg. 1992;161:87-97.

9. Umaru NF, Akogun OB. Physical factors associated with Anopheles and Culex mosquitoes' survival in captivity in Yola, Nigeria. Int J Mod Biol Res. 2015;4(1):16-24.

10. Bakhshi H, Abai MR, Amin G, Zolfi R, Pirmohammadi M, Bakhshi A, et al. Larvicidal properties of botanical extracts of Lawsonia inermis against Anopheles stephensi. Adv Infect Dis. 2014;4(04):178.

11. Turner JR, Thayer J. Introduction to analysis of variance: design, analyis \& interpretation. Sage Publications; 2001.

12. Finney DJ. Probit analysis: a statistical treatment of the sigmoid response curve. Cambridge university press, cambridge; 1952.

13. Zidan ZH, Abdel-Megeed MI. New approaches in pesticides and insect control. Sun, J. 1988;78-85.

14. Zayed ABB, Szumlas DE, Hanafi HA, Fryauff DJ, Mostafa AA, Allam KM, et al. Use of bioassay and microplate assay to detect and measure insecticide resistance in field populations of Culex pipiens from filariasis endemic areas of Egypt. J Am Mosq Control Assoc. 2006;22(3):473-82.

15. Saleh MS, El-Meniawi FA, Kelada NL, Zahran HM. Resistance development in mosquito larvae Culex pipiens to the bacterial agent Bacillus thuringiensis var. israelensis. J Appl Entomol. 2003;127(1):29-32.

16. El-Shourbagy NM, Hussein MA, El-Dahab FFA, El-Monairy OM, El-barky NM. Photosensitizing effects of certain xanthene dyes on Culex pipiens 
larvae (Diptera-Culicidae). Int J Mosq Res 2018; 5 5157. 2018;

17. Carpenter TL, Respicio NC, Heitz JR. Comparative phototoxicity of soluble and insoluble forms of xanthene dyes against Culex mosquito larvae. Environ Entomol. 1984;13:1366-70.

18. Dondji B, Duchon S, Diabate A, Herve JP, Corbel V, Hougard J-M, et al. Assessment of laboratory and field assays of sunlight-induced killing of mosquito larvae by photosensitizers. J Med Entomol. 2005;42(4):652-6.

19. Barbieri A. Fluorescent sensitising Substances as Larvicides. The photodynamic Action of Light. Riv Malariol. 1928;7(4).

20. Tawfik MAH, Fattah HMA, Khaled AS, Attia RG. Effect of some photosensitizingcompounds on the house fly, musca domestica (Muscidae: Diptera). Eg Egypt J Exp Biol (Zoo) 2015; 11 213-217.

21. Khater HF, Hendawy NI. Photoxicity of rose bengal against the camel tick, Hyalomma dromedarii. Int J Vet Sci. 2014;3(2):78-86.

22. El-Ghobary A, Khafagy IF, Ibrahim ASM. Potency of some Photosensitizing Compounds against the Cotton Leaf Worm, Spodoptera littoralis (Boisduval) in Relation to some Biochemical Aspects. J Plant Prot Pathol. 2018;9(3):187-93.

23. Aref NB. Effect of rose bengal on Hylemyia antiqa (Meigen)(Diptera: Anthomyiidae). J Am Sci. 2010;6(8):27-30.

24. Hamblin MR. Antimicrobial photodynamic inactivation: a bright new technique to kill resistant microbes. Curr Opin Microbiol. 2016;33:67-73.

25. Almeida A, Cunha Â, Gomes N, Alves E, Costa L, Faustino MAF. Phage therapy and photodynamic therapy: low environmental impact approaches to inactivate microorganisms in fish farming plants. Mar Drugs. 2009;7(3):268-313.

26. Baptista MS, Wainwright M. Photodynamic antimicrobial chemotherapy (PACT) for the treatment of malaria, leishmaniasis and trypanosomiasis. Brazilian J Med Biol Res. 2011;44(1):1-10.

27. Jori G, Magaraggia M, Fabris C, Soncin M, Camerin M, Tallandini L, et al. Photodynamic inactivation of microbial pathogens: disinfection of water and prevention of water-borne diseases. J Environ Pathol Toxicol Oncol. 2011;30(3).

To cite this article: Mohamed S. Younis , Hanem F. Khater , Atef H. Hussein , Shaimaa M. farag ${ }^{c}$, Heba M Aboelela , Gehan A. Rashed. The Potential Role of Photosensitizers in Fight against Mosquitoes: Phototoxicity of Rose Bengal against Culex Pipiens Larvae, BMFJ 2021;38 (academic issue):1-10. DOI:10.21608/bmfj.2020.28574.1252 